\title{
What are the Commonly Used UML Modelling Tools in Health Informatics? A survey
}

\author{
M. Rajoo (Mageswari Rajoo), N. M. Mohamad Noor (Noor Maizura binti Mohamad \\ Noor), S. Subramaniam (Selvaraj Subramaniam)
}

Original Article

School of Informatics and Applied Mathematics (PPIMG), University Malaysia Terengganu

\section{E-mail address:}

ppimg@umt.edu

\section{Reprint address:}

Mageswari Rajoo

School of Informatics and Applied Mathematics (PPIMG),

University Malaysia Terengganu,

21030 Kuala Terengganu, Terengganu

Malaysia

Suource: Clinical Social Work and Health Intervention

Volume: 8

Issue: 2

Pages: $44-49$

Cited references: 26

\section{Reviewers:}

Vladimir Krcmery

St. Elisabeth University of Health and Social Sciences, Bratislava, Slovakia

Gyorgy Herdics

Missionary in Hegyeshalom, Hungary

\section{Key words:}

Unified Modelling Language (UML), Health informatics (HI), Information science.

\section{Publisher:}

International Society of Applied Preventive Medicine i-gap

CSWHI 2017; 8(2): 44 - 49; DOI 10.22359/cswhi_8_2_09 @ 2017 Clinical Social Work and Health Intervention

\section{Abstract:}

There are literally many UML Modelling Tools (open-source and commercial) available. While the primary use of a UML Modelling is to enable drawing UML diagrams, the newer UML Modelling Tools step into making things a lot easier by providing supporting features such as code generation, reverse engineering and model transformation. Health Informatics (HI) is not just the use of computers in Healthcare but it is 
the Information Science in the Healthcare field. Modelling Tools for HI purposes cannot afford to overwhelm its experts with model formalism which is the main objective of this paper. Thus, the following question arises: what are the commonly used UML Modelling Tools for HI? In this paper, we would provide the answer by means of systematic reviews of UML Modelling Tools used in HI projects. We assess by means of survey on related literature from journals and conference publications.

\section{Introduction}

A UML Tool or UML Modelling Tool is a software application that supports some or all of the notation and semantics associated with the UML; the industry standard general purpose Modelling language for software engineering[1]. A system which is given careful thought during a design phase of the SDLC covers the basics of software design principles and caters for correctness and completeness of a system[2]. UML Modelling Tools help software designers to model their ideas into visual designs. There are numerous commercial and open-source Tools available to support UML Modeling. These available Modelling Tools vary in terms of price and their features. Healthcare is an ever-changing Science[3]. HI is the study of information issues in the Healthcare domain and not just the use of computers in Health-care. HI has grown considerably fueled by advancements in both Healthcare and computer information technologies. New improved systems and emerging research infrastructures are being developed to ensure that HIs can also be used for secondary purposes such as clinical research, including the design and execution of clinical trials for new medicines. Since UML was made a standard in 1977, the number of UML Tools in the market has increased incredibly[1]. This definitely gives a wider choice for the software developers but at the same time requires much more time spent in the selection process of the appropriate UML Modelling Tool. UML models are easy to understand, are amenable to mechanized analysis to check critical properties and can be used to synthesize correct executable code[4]. HI projects aim at developing a correct and complete system, as such the selection of the UML Modelling Tool for the design phase of an HI project is very crucial. This paper provides an insight into the commonly used UML Modelling Tools in HI. We will also look into the reasons for these UML Modelling Tools to be widely used in HI. In this paper, first we present the results of our survey, by focusing on the usage level of different UML Modelling Tools in HI by covering conference publications, journals and books, followed by assessment on why these UML Modelling Tools are used in HI. Then the results of the survey are presented and finally concluded.

\section{Literature Review}

There is an abundance of literature discussing and comparing UML Tools if you search the internet. A direct question "What is the best UML Tool ?" is discussed in a forum at Stock Overflow[5] where people from different backgrounds (software developers to end-users) discuss their opinion on this subject. There is also a Blog[6] where the blogger did a comparison of 8 free UML Tools in hope of giving the reader an idea about what each of the Tools can do so as to make it easier to choose. The author went on to give his personal view on the best free UML Tool, for throw-away diagrams-Dia, for small UML diagrams-Gaphor and for 
more complex UML Tool with a lot of functionality-Argo UML. Another website[7] compared 17 most used UML Tools or promising new ones and listed down from prices and versions to product ratings.

After a search on the Health Informatics Journal, we found a few studies in the literature that used UML Modelling Tools for the design phase of a Healthcare System[8,9]. In these papers, the authors used, MagicDraw as their choice of UML Modelling Tool but only small parts of the design phase were covered with UML Diagrams. Pahl[10] conducted a study to compare 4 Modelling Tools zOOml gmodeler, Dia and UMLet. The UML Modelling Tools were tested and validated for the process of Modelling UML based diagrams on predefined clinical care system requirements. Their results showed that all chosen Modelling Tools were usable, however only Dia and UMLet fulfilled the requirements of their study.

Three other papers[11,12,13] evaluated several UML Tools for different general purpose. Rani and Garg[11] compared four UML Modelling Tools, i.e., Argo UML, Star UML, Umbrello UML Modeller and Rational Rose based on their features. Different UML Tools were compared and Pros and Cons were presented with a case study form.

Safdar [12] conducted a study to compare three well-known Modelling Tools: IBM Rational Software Architect (RSA), MagicDraw and Papyrus. The authors, measured the productivity in terms of Modelling effort required to correctly complete a task; learnability; time; number of clicks required; memory load required for the software engineer to complete a task. The results of their experiment suggest that MagicDraw performed significantly better in terms of learnability and memory load and completeness of state machine and sequence diagram. And, it also outperformed in terms of completeness; learnability; memory load. However, the authors concluded by saying no single tool out performed another in all Modelling tasks. In[13], thirteen commercial and open-source UML Tools were evaluated to find the most suitable tool for quality-driven architecture model transformation. The evaluation was broken into two stages. In the first stage, the Tools were studied from vendor's website to find the most promising Tools for further study and in the second stage, three of the most promising Tools were selected where the support for model-driven architecture and extensibility were observed. Ultimately, Telelogic Tau/ Developer was considered the most suitable.

Nearly all of the above discussed studies did comparisons of UML Tools based on general overall use. There is only one reported experiment to compare UML Modelling Tools for clinical pathways used in Healthcare Systems[10]. We believe that such evaluation is crucial to help software engineers and Health Informatics professionals to select a particular tool.

\section{Method}

The number of UML Tools in the market has increased incredibly, since UML was made a standard in 1997[1,14]. It is essential to find a suitable Modelling Tool in HI projects and selecting the most suited UML Tool is not an easy task especially if the projects have to be completed in a short time period.

The survey was designed with the goal of finding which UML Tools are commonly used in HI practice. The first step to conduct a survey is identifying a target. The target for this study consists of sources concerning UML Tools and HI. The sources are journals and conference publications. To sample the target and select the sources to consider in our study we, conducted a systematic 
search performed using Internet resources, Web search engines and HIJ search. The inclusion criteria adopted can be common for all kinds of sources or specific[15]. For all the sources searched the inclusion criteria, terms were "UML Tools", "UML Modelling Tools", "UML Tools in Healthcare". For the search in the HIJ website, only the search term "UML" was used. for Google Scholar the search was from years 2010 to 2016. As for the Tools, both commercial and non-commercial Tools were included. There were no particular exclusion criteria.

Google Search: We started off with the search term "Unified Modelling Language Tools" and the first feedback was from Wikipedia containing 49 UML Tools. We continued by searching Google Scholar to find UML Tools related to Healthcare Information. Then, several different search methods were applied using different combinations of strings. From the long list of publications ordered we struck-out publications not satisfying from the inclusion criteria explained above. Almost all of the publications for the term search "UML Tools" were mainly on comparisons and evaluations of UML Tool s or UML Modelling Tools. Only one publication[10] suited our mission for this paper.
HIJ Search: A search for the search term "UML Tool" and also full text field filled as "UML Tool" and sorted by best match, resulted with 9 publications from year 20002013. After filtering based on the inclusion criteria two publications were shortlisted $[8$, 9].

\section{Results}

We have to agree with Cabot[16] that there is no one best UML Tool. In general, the question on what is the best UML Tool depends on how one plans to use it. From the systemic literature review carried out for this paper, twelve UML Tools were mentioned. In Table 1, these mentioned UML Tools were summarized for their usage and reviews from the literature survey.

When considering the totality of the sources, the more UML Tools used are considered to be the commonly used Tools for the purpose of this paper. The results show that MagicDraw and ArgoUML were the most used Tools, the least used were $G a$ phor, Umbrello, Rational Rose, IBM Rational Software Architect (RSA) and Papyrus. UMLet comes as second most commonly used UML Tool and Dia, third.

Table 1: Summary of the Survey Result

\begin{tabular}{|l|l|l|l|l|l|l|l|l|l|}
\hline UML Tool & Ref 5 & Ref 6 & Ref 7 & Ref 8 & Ref 9 & Ref 10 & Ref 11 & Ref 12 & Ref 13 \\
\hline Dia & & & & & & & & & \\
\hline MagicDraw & & $*$ & & & & $*$ & & & \\
\hline ArgoUML & $*$ & $*$ & $*$ & & & & $*$ & & $*$ \\
\hline Gaphor & & $*$ & & & & & & & \\
\hline zOOml & & & & & & $*$ & & & \\
\hline UMLet & & & $*$ & & & & $*$ & & \\
\hline StarUML & & & & & & $*$ & & & \\
\hline gModeller & & & & & & & $*$ & & \\
\hline Umbrello & & & & & & & $*$ & & \\
\hline Rational Rose & & & & & & & & $*$ & \\
\hline IBM (RSA) & & & & & & & & $*$ & \\
\hline Papyrus & & & & & & $*$ & & & $*$ \\
\hline
\end{tabular}




\section{Discussion}

To apply UML in practice we need to make a critical decision about the selection of the appropriate tool for the analysis and design phase of the software development life cycle (SDLC) especially when it involves HI projects.(9-13) In this paper, we have studied, by means of a survey, how commonly a particular UML Tool is used in HI projects. This paper only investigated the commonly used UML Tool in HI projects from the listed sources. However, the reasons for these Tools to be commonly used in HI was not explored. We are now investigating the reasons for the common usage of UML Tools in HI projects.

\section{References}

1. JACK W REEVES. UML Tool - Wikipedia http://www.developerdotstar.com/mag/article.

2. PRESSMAN R S, BRUCE M (2014). Software Engineering: A Practitioner's Approach $8^{\text {th }}$ Edition McGraw-Hill Education, January 23.

3. COIERA E (2015). Guide to Health Informatics, $3^{\text {rd }}$ Edition CRC Press.

4. JURJES J, FERNANDEZ E B, FRANCE R B, HEITMEYER B R C (2004). Critical Systems Development Using Modelling Languages (CSDUML'04): Current Developments and Future Challenges $3^{\text {rd }}$ International Workshop.

5. STACK OVERFLOW What's the best UML diagramming tool? stackoverflow.com.

6. COEN T (2014). Comparison of free UML Tools Blog Software-talk.org Berlin 2014/ 05/03.

7. KIMULI D, MIKLOSKOVA M, SPANIK S, SUVADA J, ADAMCOVA J, TOMANEK P, KAFKOVA J, CZARNECKI P (2016). Social Pathology II. Warszaw, Management University, 2016. pp.: 455.

8. KAFKOVA J, SILHAROVA B, KRCMERY V, ABDO HASAN A (2017). Late presenters among HIV-positive patients, attending a rural comprehensive care clinic in Southern Uganda. ECCMID 2017.

9. SZABO I, KULKOVA N, SOKOLOVA J, MIKOLASOVA G, SUVADA J, KALAVSKA A, DOBRODENKOVA S, MATEICKA F, KAFKOVA J, NKONWA I (2013). Neurologic complications and sequellae of infectious diseases in Uganda and Kenya: Analysis of 288 cases from two rural hospitals. In Neuroendocrinology Letters Vol. 34, Suppl 1, 2013, Pages 28-31.

10. GREY E, HARDY M, SLADECKOVA V, ADAMCOVA J, BUCKO L, BLASKOVIC J, PAUEROVA K, DUDASOVA T, POLONOVA J, RABAROVA L, BENCA J (2013). Neurologic disorders in HIV-positive orphans: 10 years of follow up. Neuroendocrinology Letters Vol. 34, Suppl 1, 2013, Pages 36-40.

11. BENCA J, ONDRUSOVA A, ADAMCOVA J, TAKACOVA M, POLONOVA J, TAZIAROVA M (2007). Ten years experience with 497 cases of neuroinfections in tropic: in limited laboratory infrastructure initially treat both, cerebral malaria and meningitis. Neuroendocrinology Letters Vol. 28, Suppl 2, June 2007, Pages49-50.

12. MULI J M, SECKOVA S, SLADECKOVA V, ADAMCOVA J, RABAROVA L, TAKACOVA M, POLONOVA J, DUDASOVA T, PAUEROVA K, NAMULANDA V, OKOTH V, JUMA O, DIANA E, JOHNSON J, DEADLINE J, BARTKOVJAK M, KOLENOVA A, TAZIAROVA M, BENCA J, NJAMBI Z (2007). Meningococcal meningitis is still the commonest neuroinfection in the community in tropics: overview of 62 cases. Neuroendocrinology letters Vol 28, Suppl 3, Nov 2007, Pages 23-24.

13. MULI J M, SECKOVA S, SLADECKOVA V, STENO J, ADAMCOVA J, RABAROVA L, TAKACOVA M, POLONOVA J, DUDASOVA T, PAUEROVA K, NAMULANDA V, OKOTH V, JUMA O, DIANA E, JOHNSON J, DEADLINE J, BARTKOVJAK M, KOLENOVA A, TAZIAROVA M, 
BENCA J, NJAMBI Z (2007). Meningitis in diabetic patients. Neuroendocrinology letters Vol 28, Suppl 3, Nov 2007, Pages 28-29.

14. POLONOVA J (2015). Respiratory infections after camping in free nature are the current diseases in Migrants to Austria and Germany via Hungary in September 2015: Experience from Roszke and Vamoszabadi. In Krcmery V, Liskova A, Mrazova M, Herdics G, Khali I, Polonova J, Suvada J, Bucko L, Bibza M, Ondova P, Hajj P, Fer I. Clinical Social Work, 2015; 5(2 2015) 33-35. ISSN:2222-386X.

15. BELOVICOVA M, ADAMCOVA J, KAFKOVA J ET ALL (2017). Low incidence of MRSA among úphysiotherapy patients. Clin Soc Work Health Intervention, vol.8.2017,1,33-35. ISSN 2076-9741/Online.

16. POLONOVA J (2015). Self-acceptance, self-esteem building and experiencing of healthy sexuality among youth as the prevention of an abuse in partnerships In Suvada, J. - Tomanek, P. (eds.), 2015. Social pathology among youth (abstract book). Bratislava: St. Elisabeth University of Health and Social Work Bratislava, 2015. ISBN 978-80-8132-131-3. 73 - 74 p.

17. SOCIALCOMPARE (2015). UML Tool s Comparison Tables", socialcompare.com.

18. OSAMOR V C, AZETA A A, AJULO O O (2014). Tuberculosis-Diagnostic Expert System: an architecture for translating patients information from web for use in tuberculosis diagnosis Health Informatics J Dec 275-87. Epub.
19. AUSTIN T, SUN S (2013). Evaluation of ISO EN 13606 as a result of its implementation in WML Health Informatics J. Dec. 19(4).

20. BAK T, MIERZWA J, JURJEWICZ H (2015). Religion and Spirituality in Social Work Practice. New Jersey 2015. 101 s. ISBN 978-0-9967396-2-7.

21. PAHL CH, SUPRIYANTO E, DETSCHEW V (2015). Evaluation of UML Modelling Tools for clinical pathways used in health information systems DOI: July 10.1109/ CISTI.2015.7170540.

22. RANI T, GARG S (2013). Comparison of different UML Tool: Tool approach International Journal Of Engineering And Computer Science, Vol 2 pg.1900-1908.

23. AQEEL S, IQBAL M Z, KHAN M $\mathrm{U}$ (2015). Empirical Evaluation of UML Modelling Tools - A Controlled Experiment ECMFA, LNCS 9153, pp.33-44.

24. MERILINNA J, MATINLASSI M. Evaluation of UML Tool s for Model-Driven Architecture

25. SHIBI M T (2004). Evaluation of UML Tool $s$ using an end-to-end application.

26. REGGIO G, LEOTTA M, RICCA F, CLERISSI D (2013). What are the used UML diagrams? A Preliminary Survey Experiences and Empirical Studies in Software Modelling (EESSMod 2013) October.

27. CABOT J (2011). What is the best open source UML designing tool? www.quora. com. 